\title{
Coordination Polymers Constructed from Oligonuclear Nodes
}

\author{
Marius Andruh*
}

\begin{abstract}
The node-and-spacer approach is widely employed in crystal engineering to construct coordination polymers. It consists of self-assembly processes involving mononuclear cationic species and exo-dentate ligands. We enlarged this strategy using preformed homo- and heterometallic complexes as nodes. The presence of two or more metal ions within a node leads to novel network topologies, as well as to new properties, arising from the intra- and internode interactions. This paper reviews some representative examples of coordination polymers obtained in our laboratory and constructed from: i) binuclear alkoxo-bridged complexes; ii) heterometallic 3d-3d' and $3 d-4 f$ complexes.
\end{abstract}

Keywords: Coordination polymers · Node-and-spacer

\section{Introduction}

The construction of coordination polymers represents an important topic in crystal engineering. ${ }^{[1]}$ In 1990, Robson founded a general strategy for obtaining coordination polymers in a rational way, known as the node-and-spacer approach, ${ }^{[2]}$ which consists of self-assembly processes involving mononuclear cationic species (assembling cations) and exo-dentate (divergent) ligands. The judicious choice of the metal ions and spacers leads to molecular materials with interesting and, eventually, technologically useful properties. The metal ions play a double role: a structural one, since they impose, through their stereochemical preference, the resulting network topology, and a functional one, carrying the magnetic, optical, catalytic and other physical or chemical properties. The ligands used as spacers, through their denticity, shape, electronic structure, play a crucial role as well, sustaining the solid-state architectures and mediating the interaction between the metal centers. Oligonuclear complex species can also act as nodes. The incorporation of the oligonuclear complexes into extended frame-

\footnotetext{
${ }^{*}$ Correspondence: Prof. Dr. M. Andruh

Inorganic Chemistry Laboratory, Faculty of Chemistry

University of Bucharest

Str. Dumbrava Rosie nr. 23

020464-Bucharest, Romania

E-mail: marius.andruh@dnt.ro
}

works occurs through:[3] i) formation of the nodes in a preliminary step, followed by the reaction with appropriate spacers; ii) formation of the nodes as a result of the interaction of the metal ions with the spacer; iii) serendipitous assembly of the metal ions into clusters which are then interconnected by spacer molecules. The chemistry we developed in our laboratory follows the first method. Two types of nodes have been employed: i) binuclear alkoxo-bridged copper(II) complexes; ii) homo- and heterometallic (3d-3d'; 3d-4f) oligonuclear species obtained using compartmental ligands. The metal ions interact with the divergent ligand through their easily accessible coordination sites.

\section{Coordination Polymers Constructed from Binuclear Alkoxo-bridged Copper(II) Complexes}

Alkoxo-bridged copper(II) dimers act efficiently as nodes. ${ }^{[4,5]}$ They are spontaneously generated by reacting a copper salt with an aminoalcohol: monoethanolamine (Hmea), propanolamine (Hpa), diethanolamine $\left(\mathrm{H}_{2} \mathrm{dea}\right)$, triethanolamine $\left(\mathrm{H}_{3}\right.$ tea $)$, etc. The spacer molecules replace the weakly coordinated anions or solvent molecules. The lower the denticity of the aminoalcohol, the higher the dimensionality of the resulting coordination polymer. ${ }^{[4]}$ For example, bidentate aminoalcohols, such as monoethanolamine or propanolamine, are suited for the construction of two-dimensional (2D) coordination polymers, while tridentate aminoalcohols (e.g. diethanolamine), which block three coordination positions at the pentacoordinated copper ions, will generate one-dimensional (1D) coordination polymers. Various molecules can be used as spacers, either neutral (pyrazine, poly-pyridyl derivatives) or anionic (polycarboxylato anions, poly-cyanidometal complexes). Let us consider the following binuclear nodes: $\left\{\mathrm{Cu}_{2}(\mathrm{mea})_{2}\right\}^{2-}$, $\left\{\mathrm{Cu}_{2}(\mathrm{pa})_{2}\right\}^{2-}$, and $\left\{\mathrm{Cu}_{2}(\text { Hdea })_{2}\right\}^{2-}$, which result from the reaction of copper salts (perchlorate, tetrafluoroborate) with bidentate ligands (monoethanolamine, Hmea, propanolamine, Hpa) and a tridentate aminoalcohol (diethanolamine, $\mathrm{H}_{2} \mathrm{dea}$ ). The interaction between the first two binuclear nodes with rigid linear spacers (pyrazine, 4,4'-bipyridine, bis(4-pyridyl)ethylene, $\left.\left[\mathrm{Au}(\mathrm{CN})_{2}\right]^{-}\right)$affords cationic or neutral 2D coordination polymers (Fig. 1a, b), while the third one generates cationic chains (Fig. 1c). The charges of the coordination networks are balanced by uncoordinated anions. It is important to mention that, in some cases, the expected dimensionality is reduced when the anion or the solvent molecule are strongly coordinated to one of the two available coordination sites of the copper ion in $\left\{\mathrm{Cu}_{2}(\mathrm{mea})_{2}\right\}$ and $\left\{\mathrm{Cu}_{2}(\mathrm{pa})_{2}\right\}$ nodes. ${ }^{[5 e]}$

An important factor to be considered for solids is the tendency to minimize void space within their structures. The empty space resulting from the packing of coordination polymers can be filled by: i) hosting anions, solvent molecules, uncoordinated ligand molecules; ii) interpenetration, i.e. the voids associated to one framework are occupied by one or more independent frameworks. For catalytic or sorption applications, the molecular crystals must be porous. In order to construct them, the spacers or the ancillary ligands must be anionic. Alternatively, the nodes and the spacers can both be neutral. Recently, we succeeded in obtaining a quite interesting three-dimensional (3D) coordination network by assembling neutral $\left\{\mathrm{Cu}_{2}(\text { mand })_{2}\right\}$ nodes 


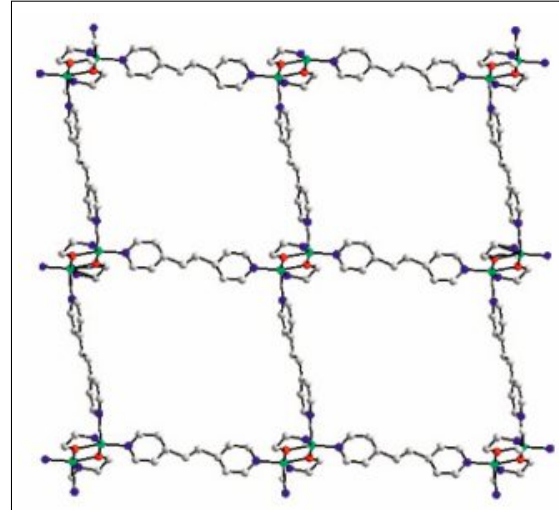

(a)

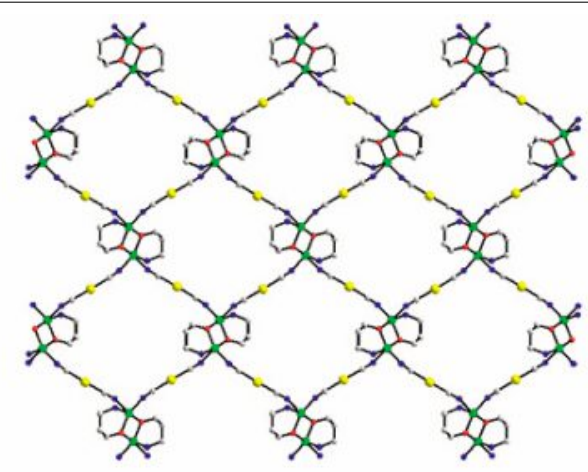

(b)

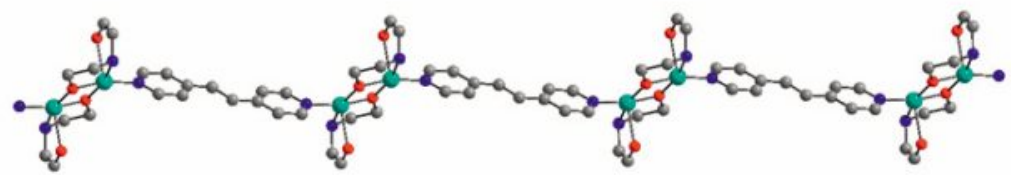

(c)

Fig. 1. Coordination polymers constructed from binuclear alkoxo-bridged nodes: (a) ${ }_{2}^{\infty}\left[\mathrm{Cu}_{2}(\mathrm{pa})_{2}(\mathrm{bpe})_{2}\right]\left(\mathrm{ClO}_{4}\right)_{2}$ (bpe = bis(4-pyridyl)ethylene); $\left.{ }^{[5 \mathrm{~b}]}(\mathrm{b}){ }_{2}^{\infty}\left[\left\{\mathrm{Cu}_{2}(\mathrm{pa})_{2}\right\}\left\{\mathrm{Au}(\mathrm{CN})_{2}\right\}_{2}\right]\right]^{[5 \mathrm{~d}]}$ (c) ${ }_{1}^{\infty}\left[\mathrm{Cu}_{2}(\mathrm{Hdea})_{2}(\mathrm{bpe})\right](\mathrm{bpe})\left(\mathrm{ClO}_{4}\right)_{2}$, one of the bpe molecules is not coordinated. ${ }^{[5 \mathrm{~b}]}$

and hexamethylenetetramine (hmt) as a spacer, $\left.{ }_{\infty}^{3}\left[\mathrm{Cu}_{2} \text { (mand) }\right)_{2}(\mathrm{hmt})\right] \cdot \mathrm{H}_{2} \mathrm{O}$ (mand $=$ the dianion of the mandelic acid). ${ }^{[6]}$ The most interesting feature of the crystal structure is the presence of channels running along the crystallographic $c$ axis (Fig. 2 ). The crystallization water molecules are hosted in these channels. Thermal analysis and XRD measurements at various temperatures show that the water molecules can be removed, the $3 \mathrm{D}$ scaffold being stable up to $280{ }^{\circ} \mathrm{C}$. Once the channels are emp-

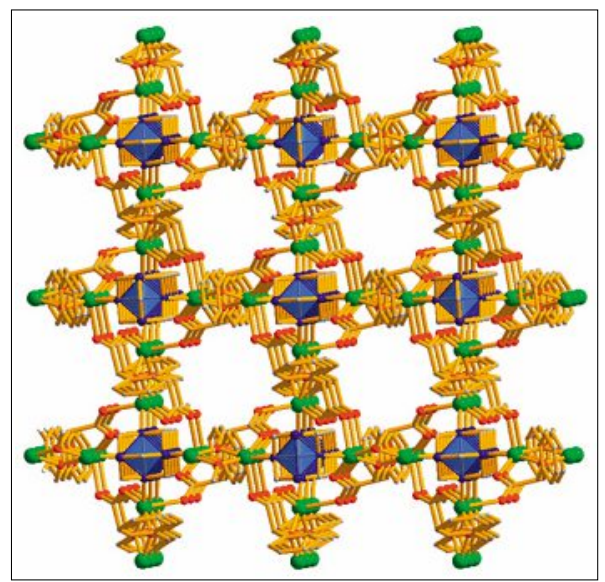

Fig. 2. Perspective view of ${ }_{\infty}^{3}\left[\mathrm{Cu}_{2}(\text { mand })_{2}(\mathrm{hmt})\right]$. $\mathrm{H}_{2} \mathrm{O}$ along the crystallographic axis $\mathrm{c}$. The hmt molecules are highlighted in blue..$^{[6]}$ The water molecules occupying the channels are not represented. tied, they can host various molecules $\left(\mathrm{H}_{2}\right.$, $\mathrm{CO}_{2}$ ): $10.9 \mathrm{~cm}^{3} \mathrm{~g}^{-1}$ for hydrogen (representing $0.09 \mathrm{wt} \%$ ) and $90.7 \mathrm{~cm}^{3} \mathrm{~g}^{-1}$ for carbon dioxide (representing $17.9 \mathrm{wt} \%$ ).

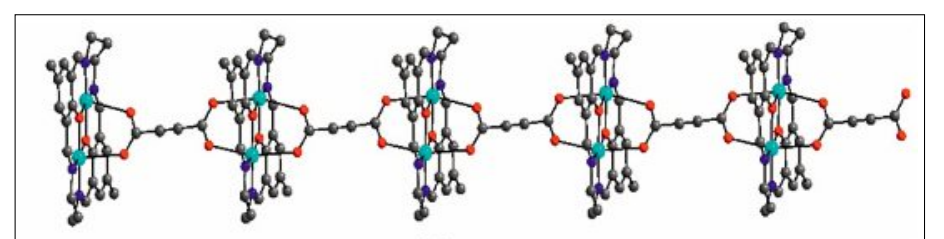

(a)

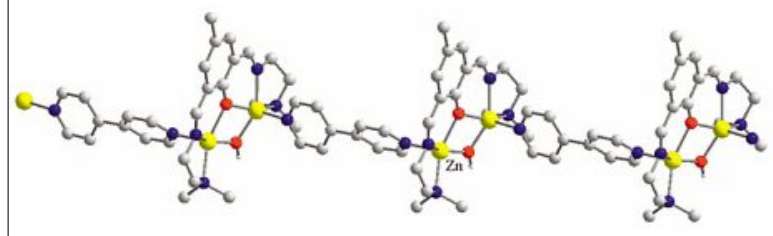

(b)

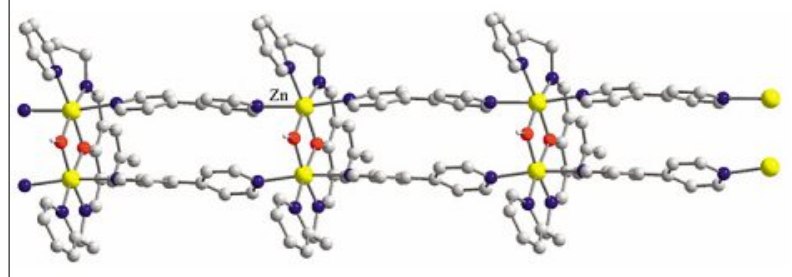

(c)

\section{Homobinuclear Tectons Constructed from Compartmental Ligands}

Stable binuclear or trinuclear nodes are easily generated using compartmental ligands. Most of them are Schiff bases resulting from the condensation reaction between appropriate poly-keto/formyl and poly-amine precursors. ${ }^{[7]}$

\section{Bicompartmental Ligands}

Such ligands are either end-off, sideoff, or macrocyclic species, most of them being obtained by reacting 2,6-diformyl$p$-cresol with various diamines. ${ }^{[7]}$ Usually, this type of ligand provides square-planar surroundings for each metal ion. In order to saturate the coordination number of the metal ions preferring, for example, square pyramidal and octahedral environments, different ligands (anions or solvent molecules) are attached. When divergent ligands are employed (e.g. bis-4-pyridyl derivatives, dicarboxylato ions) tetranuclear and polynuclear complexes are assembled. ${ }^{[8]}$ Three examples of coordination polymers obtained using $\left\{\mathrm{Cu}_{2}\right\}$ and $\left\{\mathrm{Zn}_{2}\right\}$ nodes are presented in Fig. 3. The first compound (Fig. 3a) results by assembling $\left\{\mathrm{Cu}_{2}\right\}$ nodes and the dianion of the acetylenedicarboxylic acid. ${ }^{[9]}$ The binuclear node is obtained using the macrocyclic ligand resulting from the condensation reaction of 2,6-diformyl-4-methyl-phenol with 1,3-diamino-propane. The second and the third coordination polymers are assembled from binuclear zinc complexes with endoff compartmental ligands and 4,4'-bipyridyl. In the second case the compartmental

Fig. 3. Coordination polymers constructed from binuclear $\left[\mathrm{Cu}_{2}\right]$ and $\left[\mathrm{Zn}_{2}\right]$ nodes: (a) ${ }_{\infty}^{1}\left[\mathrm{Cu}_{2} \mathrm{~L}^{2}\right.$ (acdca) $]$. $\mathrm{CH}_{3} \mathrm{OH} \cdot 4 \mathrm{H}_{2} \mathrm{O}\left(\mathrm{H}_{2} \mathrm{~L}^{1}\right.$ is the Schiff-base proligand resulting from the condensation reaction of 2,6-diformyl-4-methyl-phenol with 1,3-diaminopropane); ;9a] (b) ${ }_{1}^{\infty}\left[\left\{\mathrm{L}^{2} \mathrm{Zn} \mathrm{n}_{2}(\mathrm{OH})\right\}\left(4,4^{\prime}-\right.\right.$ bipy)] $\left(\mathrm{ClO}_{4}\right)_{2} \cdot 2 \mathrm{H}_{2} \mathrm{O}$ $\left(\mathrm{H}_{2} \mathrm{~L}^{2}\right.$ results from 2,6-diformyl4-methyl-phenol and $\mathrm{N}, \mathrm{N}$-dimethylethylenediamine);[9b] (c) ${ }_{1}^{\infty}\left[\left\{\mathrm{L}^{3} \mathrm{Zn} \mathrm{n}_{2}(\mathrm{OH})\right\}\left(4,4^{\prime}-\right.\right.$ bipy) $\left.{ }_{2}\right]\left(\mathrm{ClO}_{4}\right)_{2} \cdot 2 \mathrm{H}_{2} \mathrm{O}$ $\left(\mathrm{H}_{2} \mathrm{~L}^{3}\right.$ results from 2,6-diformyl4-methyl-phenol and 2-(2-aminoethyl)pyridine). ${ }^{[9 b]}$ 
ligand results from the Schiff condensation of 2,6-diformyl-4-methyl-phenol with $N, N$-dimethyl-ethylenediamine. The binuclear nodes are connected by only one spacer molecule (Fig. 3b), the zinc ions being pentacoordinated with a squarepyramidal stereochemistry. ${ }^{[9 b]}$ In the third compound (Fig. 3c), the binuclear nodes are connected by two spacer molecules, resulting in a ladder topology. ${ }^{[9 b]}$ The end-off compartmental ligand in this case is obtained from 2,6-diformyl-4-methylphenol and 2-aminoethyl-pyridine. We have shown that the formation of chains with single or double bridges connecting the nodes is influenced by i) the molar ratio between the node and the spacer; ii) the nature of the compartmental ligand, that is, the nature of the diamine used to obtain the Schiff-base ligand. ${ }^{[9]}$ All these zinc coordination polymers exhibit strong luminescence in visible light.

\section{Tricompartmental Ligands}

Recently, we have shown that our strategy based on binuclear nodes can be extended using $C_{3}$-symmetric trinuclear copper(II) complexes. ${ }^{[10]}$ Several families of such complexes, which can be used as tectons in crystal engineering, were obtained by Glaser et al. using tricompartmental ligands resulting from the condensation between 2,4,6-triformylphloroglucinol and various polyamines. ${ }^{[11]}$ One example is the trinuclear complex formed by the reaction of copper(II) ions and the tricompartmental Schiff-base obtained from 2,4,6-triformylphloroglucinol and $\mathrm{N}, \mathrm{N}$-dimethylethylenediamine. The selfassembly process involving these trinuclear tectons and the dicyanamide anions affords a 2D coordination polymer (Fig. 4). ${ }^{[10]}$

\section{Coordination Polymers Constructed from Heterometallic Nodes}

Binuclear complexes with different metal ions are particularly attractive as tectons in designing heterometallic coordination polymers. They combine the electronic and stereochemical peculiarities of the two metal ions. When the metal ions are paramagnetic, the intra-node exchange interactions, as well as those between the resulting spins, may lead to interesting magnetic properties. The spacers can interact with only one type of metal ion from different nodes while the second metal ion from the nodes is not involved in the linkage. They can connect one type of metal ions from a node with another type from the next node, or they can connect both metal ions from a node with the two metal ions from another node. Stable heterobi-

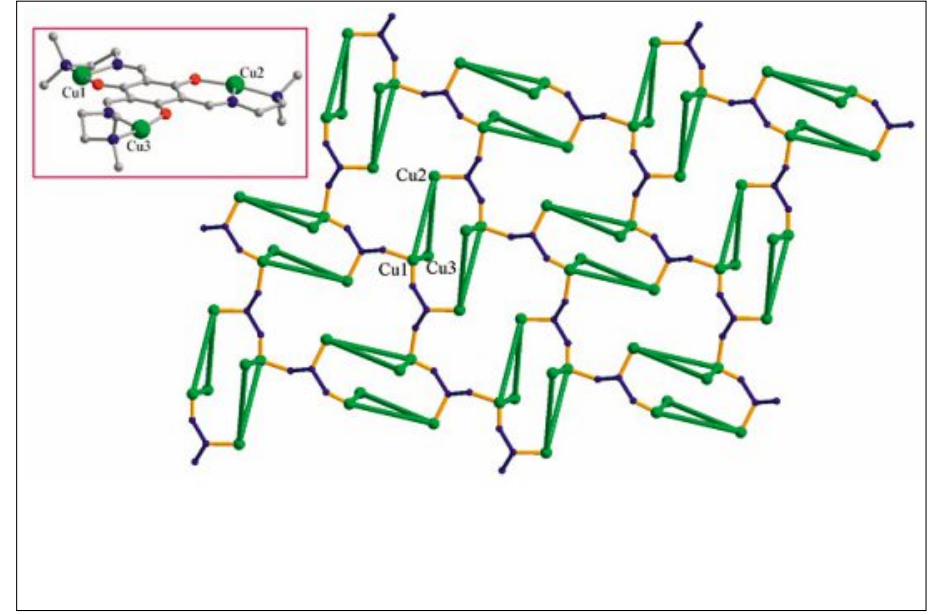

Fig. 4. A 2D coordination polymer constructed from trinuclear nodes: ${ }_{2}^{\infty}\left[\mathrm{Cu}_{3}\left(\mathrm{~L}^{4}\right)\right.$ (dca) $\left.{ }_{3}\left(\mathrm{C}_{2} \mathrm{H}_{5} \mathrm{OH}\right)\right] \cdot 2 \mathrm{H}_{2} \mathrm{O}$ $\left(\mathrm{H}_{3} \mathrm{~L}^{4}=\right.$ tricompartmental Schiff-base obtained from 2,4,6triformylphloroglucinol and $\mathrm{N}, \mathrm{N}$-dimethylethylenediamine). ${ }^{[10]}$ The trinuclear nodes are represented as green triangles; the dca spacers are drawn in blue. Inset: view of the trinuclear node.

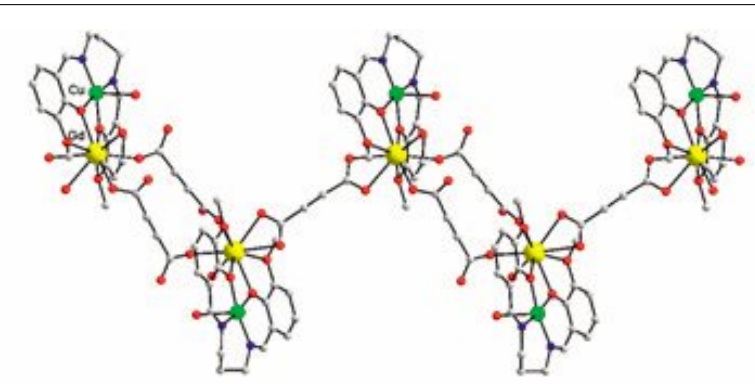

(a)

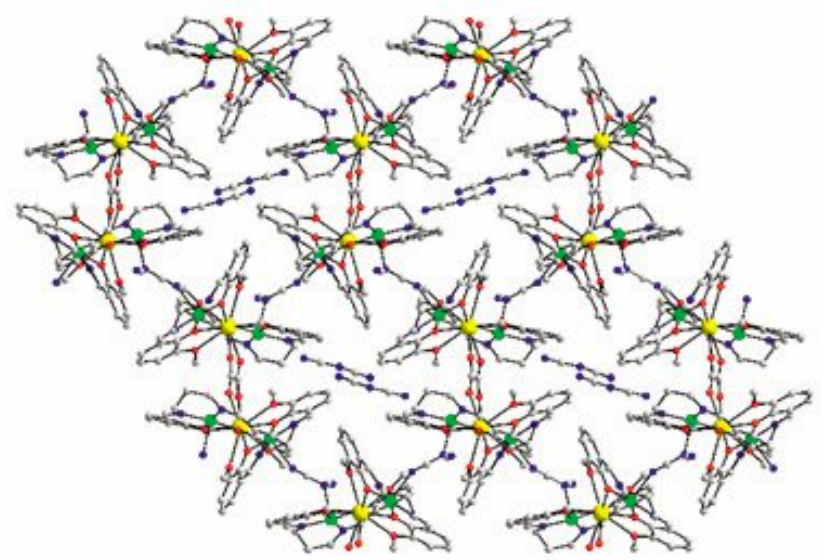

(b)

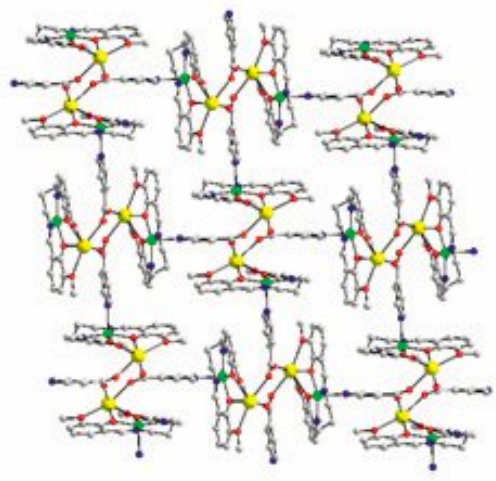

(c) polymers constructed from 3d-4f nodes: (a) ${ }_{1}^{1}\left[\mathrm{~L}^{5} \mathrm{CuGd}(\mathrm{acdca})\right.$ $\left.\left(\mathrm{H}_{2} \mathrm{O}\right)_{2}\right] \cdot 13 \mathrm{H}_{2} \mathrm{O}\left(\mathrm{H}_{2} \mathrm{~L}^{5}\right.$ = compartmental Schiff-base resulted from $o$-vanillin and 1,3-propanediamine); ${ }^{[13 a]}$ (b) ${ }_{2}^{2}\left[\left\{\left(\mathrm{~L}^{5} \mathrm{Cu}\right)_{2} \mathrm{Pr}\right\}\right.$ $\left.\left(\mathrm{C}_{2} \mathrm{O}_{4}\right)_{0.5}(\mathrm{dca})\right]$ (dca) $\cdot 2 \mathrm{H}_{2} \mathrm{O}$ (dca = the dicyanamido anion):[13a] (c) ${ }_{2}^{2}\left[\mathrm{~L}^{5} \mathrm{CuPr}\left(\mathrm{NO}_{3}\right)_{2}(\mathrm{IN})\right]$ (IN = the isonicotinato ligand). ${ }^{[13 b]}$
Fig. 5. Coordination 


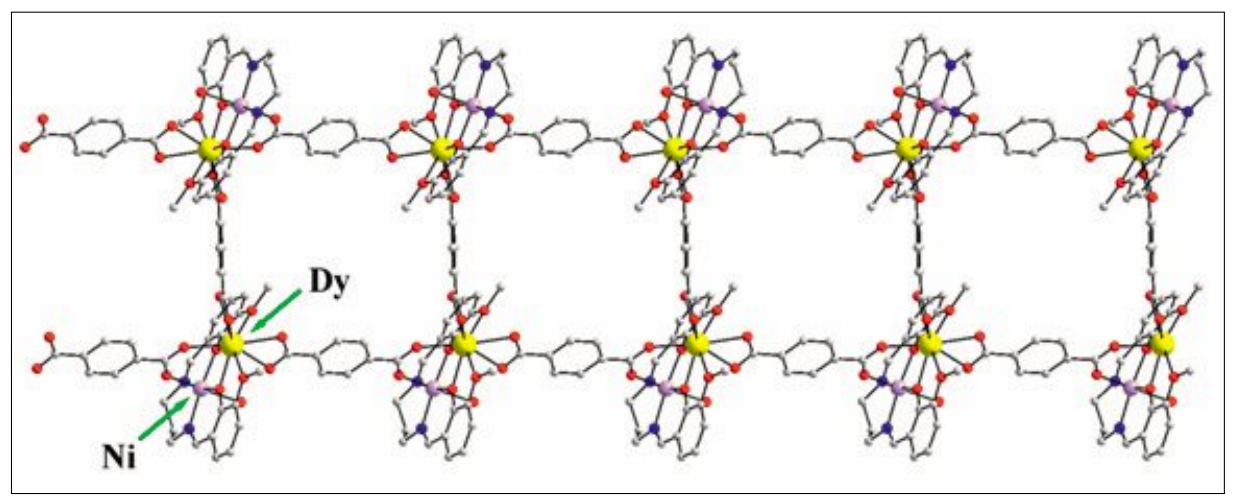

Fig. 6. 1D coordination polymer constructed from [NiDy] nodes and terephthalato bridges: $\left.{ }_{\infty}^{1}\left[{ }^{5} \mathrm{Ni}\left(\mathrm{H}_{2} \mathrm{O}\right) \mathrm{Dy}(\mathrm{tfa})_{1.5}\right]\right]^{[13 \mathrm{c}]}$

metallic nodes are readily obtained using again the compartmental ligands. They must be dissymmetric, in order to avoid the scrambling of the metal ions. We currently employ Schiff-base ligands obtained from $o$-vanillin and various diamines. These ligands are especially appropriate to obtain binuclear 3d-4f complexes, but 3d-3d' binuclear complexes can be obtained as well.

\section{Coordination Polymers \\ Constructed from 3d-4f Nodes}

We obtained a rich variety of coordination polymers using $3 \mathrm{~d}-4 \mathrm{f}$ tectons. ${ }^{[12]}$ The versatility of these building blocks is increased by the drastic difference in their chemical behavior. Consequently, they can interact selectively with various spacers. Indeed, taking the case of $\mathrm{Cu}^{\mathrm{II}}-\mathrm{Ln}^{\mathrm{III}}$ heterobinuclear complexes, the rare-earth cations are hard acids, with a strong oxophilic character, and prefer high coordination numbers, whereas copper(II) is a borderline acid with a marked tendency to adopt a more or less distorted square-pyramidal geometry. In principle, the spacers with only oxygen donor atoms will interact preferentially with the lanthanide cation, while the spacers containing only nitrogen atoms will prefer the copper(II) (or other $3 \mathrm{~d}$ metal ion). Fig. 5 illustrates three representative examples. The first compound results by connecting $[\mathrm{CuGd}]$ nodes through acetylendicarboxylato bridges. ${ }^{[13 a]}$ The oxygen atoms from the carboxylato groups are coordinated solely to the rare earth ions (Fig. $5 a)$, resulting in zigzag chains. The second compound, a 2D coordination polymer, is constructed from two types of bridges: the dicyanamido anion, with only nitrogen donor atoms, interacting with the copper ions, and the oxalato anion that connects the rare earth ions (Fig. 5b).[13a] Finally, the third compound is a $2 \mathrm{D}$ coordination polymer assembled from $[\mathrm{CuPr}]$ nodes and a spacer bearing both nitrogen and oxygen donor atoms (the isonicotinato ion).[13b] The nitrogen atom is coordinated to copper and the carboxylato oxygens to the pra- seodymium ion (Fig. 5c). Another 1D coordination polymer, showing a ladder-like topology, has been assembled from [NiDy] This compound displays interesting magnetic properties: each [NiDy] node acts as a Single Molecule Magnet.[13c] nodes and terephthalato bridges (Fig. 6).

\section{Coordination Polymers Constructed from 3d-3d' Nodes}

The second compartment of the binucleating ligands derived from $o$-vanillin can accommodate another $3 \mathrm{~d}$ metal ion. While the metal ion within the $\mathrm{N}_{2} \mathrm{O}_{2}$ compartment shows a square pyramidal $\left(\mathrm{Cu}^{\text {II }}, \mathrm{Zn}^{\text {II }}\right)$ or an octahedral symmetry $\left(\mathrm{Ni}^{\mathrm{II}}\right)$, the $3 \mathrm{~d}$ metal ion hosted into the $\mathrm{O}_{2} \mathrm{O}_{2}{ }^{\prime}$ compartment displays a strongly distorted stereochemistry, with short and long coordination bonds, the last ones involving the methoxy groups. ${ }^{[14]}$ Let us discuss here the case of two coordination polymers obtained from binuclear cations, $\left[\mathrm{Cu}^{\mathrm{II}} \mathrm{Co}^{\mathrm{II}}\right]$ and $\left[\mathrm{Ni}^{\mathrm{II}} \mathrm{Co}^{\mathrm{II}}\right]$, and dicyanamido bridges. Their structures are depicted in Fig. 7. The most striking difference between the two structures consists of their dimensionality: the first one is a 1D coordination polymer, ${ }^{[14 a]}$ whereas the second one is bidimensional, ${ }^{[14 b]}$ the molar ratio between the nodes and the spacers being the same for both compounds, 1:2. First of all, we observe that in the case of the $\mathrm{Cu}^{\mathrm{II}} \mathrm{Co}^{\mathrm{II}}$ derivative there are two types of dicyanamido ligands: bridging, con-

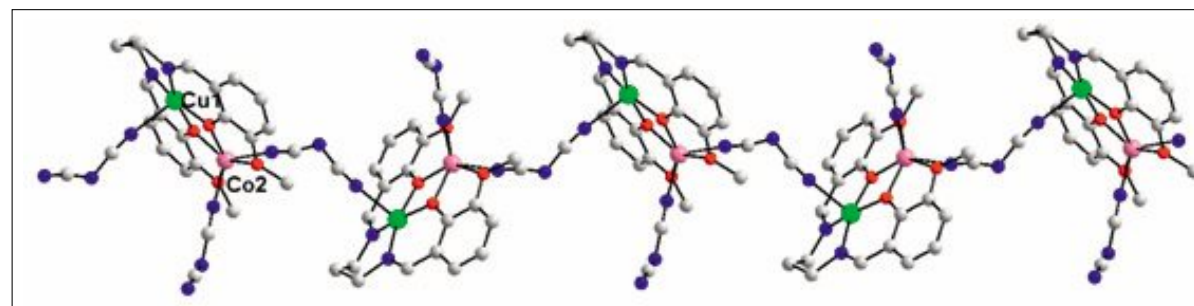

(a)

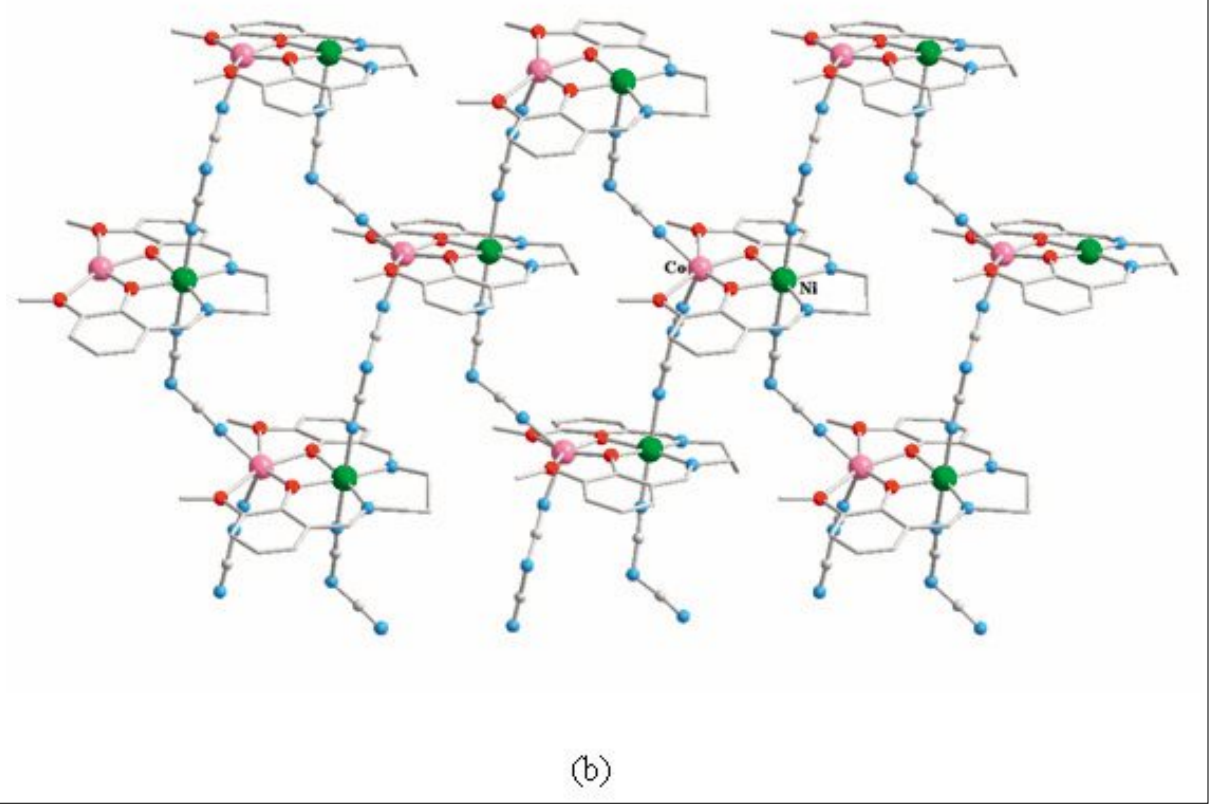

Fig. 7. Coordination polymers constructed from $3 d-3 d$ ' nodes and dicyan amido spacers: (a) ${ }_{\infty}^{1}\left[\mathrm{~L}^{5} \mathrm{CuCo}(\mathrm{dca})_{2}\right] ; ;^{[14 a]}(\mathrm{b})^{2}{ }_{\infty}\left[\left[{ }^{5} \mathrm{NiCo}(\mathrm{dca})_{2}\right] \cdot{ }^{[14 b]}\right.$ 
necting one copper ion from a node with the cobalt ion from another one, and terminal, coordinated to the cobalt ion; we also notice that the stereochemistry of the copper ion is square-pyramidal. In order to increase the dimensionality of the heterometallic coordination polymer (from 1D to $2 \mathrm{D}$ ), the terminal bridging dicyanamido ligand must be coordinated to the sixth coordination site of the metal ion lying in the first, $\mathrm{N}_{2} \mathrm{O}_{2}$, compartment. This is possible by replacing $\mathrm{Cu}^{\mathrm{II}}$ with a metal ion showing a strong preference for six-coordination, for example $\mathrm{Ni}^{\mathrm{II}}$. Indeed, starting from the $\left[\mathrm{Ni}^{\mathrm{II}} \mathrm{Co}^{\mathrm{II}}\right]$ complex, the expected $2 \mathrm{D}$ coordination polymer is obtained (Fig. 7b). Moreover, its magnetic properties are quite interesting, this compound being a molecular magnet below $12 \mathrm{~K}$. Other $3 \mathrm{~d}-3 \mathrm{~d}$ ' coordination polymers have been obtained in our laboratory using thiocyanato, di- and tricarboxylato ligands, as well as cyanidocomplexes as metalloligands. ${ }^{[14]}$

\section{Conclusions}

The examples selected in this paper illustrate the rich variety of coordination polymers that can be constructed from oligonuclear tectons. Many other oligonuclear tectons can be designed or can be found in literature. The heterometallic systems constructed from paramagnetic metal ions have particular relevance in molecular magnetism. Moreover, the heterobimetallic nodes can be connected through metalloligands resulting in heterotrimetallic complexes. We have recently shown that a rational way towards heterotrimetallic Single Chain Magnets consists of selfassembly processes involving anisotropic high-spin nodes and paramagnetic metalloligands. ${ }^{[15]}$ This strategy opens interesting perspectives in the field of molecular nano-magnets. Luminescent materials can be obtained using $\mathrm{Zn}^{\mathrm{II}} \mathrm{Ln}^{\mathrm{III}}$ nodes, the zinc-ligand moiety acting as an efficient antenna. ${ }^{[16]}$

\section{Acknowledgements}

I would like to express my gratitude to all my co-workers, colleagues, and students. Their names appear in the references listed.

Received: February 6, 2013

[1] See, for example: a) M. O'Keeffe, O. M. Yaghi, Chem. Rev. 2012, 112, 675; b) N. Stock, S Biswas, Chem. Rev. 2012, 112, 944; c) G. Férey, C. Serre, Chem. Soc. Rev. 2009, 38, 1380; d) W. L. Leong, J. J. Vittal, Chem. Rev 2011, 111, 688; e) S. Horike, S. Shimomura, S. Kitagawa, Nat. Chem. 2009, 1, 695; f) X. Lin, J. Jia, P. Hubberstay, M. Schröder, N. R. Champness, CrystEngComm. 2007, 9, 438; g) C. Janiak, Dalton Trans. 2003, 2781; h) H. W. Roesky, M. Andruh, Coord. Chem. Rev. 2003, 236,91 ; i) B. Moulton, M. J. Zaworotko, Chem Rev. 2001, 101, 1629; j) D. Braga, F. Grepioni, Chem. Commun. 2005, 3635; k) S. Kitagawa, R. Kitaura, S. Noro, Angew. Chem., Int. Ed. 2004, 43, 2334; 1) M. Andruh, C. Ruiz-Perez, in 'Macromolecules Containing Metals and MetalLike Elements: Inorganic Supramolecular Assemblies', Vol. 9: 'Supramolecular and SelfAssembled Metal-Containing Materials', Chap. 10, Eds. A. S. Abd-El-Aziz, C. E. Carraher, Jr., C. U. Pittman, Jr., M. Zeldin, WileyInterscience, Hoboken, NJ, 2009, pp. 451; m) D. Bradshaw, J. B. Claridge, E. J. Cussen, T. J. Prior, M. J. Rosseinsky, Acc. Chem. Res. 2005, 38, 273.

[2] a) R. W. Gable, B. F. Hoskins, R. Robson, $J$. Chem. Soc., Chem. Commun. 1990, 1677; b) B. F. Hoskins, R. Robson, J. Am. Chem. Soc. 1990, 112,1546

[3] M. Andruh, Chem. Commun. 2007, 2565.

4] M. Andruh, Pure Appl. Chem. 2005, 77, 1685.

[5] a) G. Marin, V. Ch. Kravtsov, Iu. A. Simonov, V. Tudor, J. Lipkowski, M. Andruh, J. Molec. Struct. 2006, 796, 123; b) G. Marin, V. Tudor, V. Ch. Kravtsov, M. Schmidtmann, Yu. A. Simonov, A. Müller, M. Andruh, Cryst. Growth \& Des. 2005, 5, 279; c) V. Tudor, G. Marin, V. Kravtsov, Yu. A. Simonov, J. Lipkowski, M. Brezeanu, M. Andruh, Inorg. Chim. Acta 2003, 353, 35; d) C. Paraschiv, M. Andruh, S. Ferlay, M. W. Hosseini, N. Kyritsakas, J.-M. Planeix, N. Stanica, Dalton Trans. 2005, 1195; e) G.
Marin, M. Andruh, A. M. Madalan, A. J. Blake, C. Wislon, N. R. Champness, M. Schröder, Cryst. Growth \& Des. 2008, 8, 964.

[6] E. Ilyes, M. Florea, A. M. Madalan, I. Haiduc, V. I. Parvulescu, M. Andruh, Inorg. Chem. 2012, 51, 7954.

[7] See, for example: a) P. Zanello, S. Tamburini, P. A. Vigato, G. A. Mazzocchin, Coord. Chem. Rev. 1987, 77, 165; b) P. A. Vigato, S. Tamburini, Coord. Chem. Rev. 2004, 248, 1717; c) P. A. Vigato, S. Tamburini, L. Bertolo, Coord. Chem. Rev. 2007, 251, 1311; e) P. A. Vigato, S. Tamburini, Coord. Chem. Rev. 2008, 252, 1871; f) R. Robson, Dalton Trans. 2008, 5113 .

[8] M. Andruh, D. G. Branzea, R. Gheorghe, A. M. Madalan, CrystEngComm. 2009, 11, 2571

[9] a) M. Pascu, M. Andruh, A. Müller, M. Schmidtmann, Polyhedron 2004, 23, 673; b) G. Marinescu, G. Marin, A. M. Madalan, A. Vezeanu, C. Tiseanu, M. Andruh, Cryst. Growth \& Des. 2010, 10, 2096.

[10] A. E. Ion, S. Nica, A. M. Madalan, F. Lloret, M. Julve, M. Andruh, CrystEngComm. 2013, 15 , 294.

[11] T. Glaser, Coord. Chem. Rev. 2013, 257, 140.

[12] M. Andruh, Chem Commun. 2011, 47, 3025.

[13] a) R. Gheorghe, P. Cucos, M. Andruh, J.-P. Costes, B. Donnadieu, S. Shova, Chem.-Eur. J. 2006, 12, 187; b) R. Gheorghe, M. Andruh, A. Müller, M. Schmidtmann, Inorg. Chem. 2002, 41, 5314; c) T. D. Pasatoiu, M. Etienne, A. M. Madalan, M. Andruh, R. Sessoli, Dalton Trans. 2010, 39, 4802.

[14] a) D. G. Branzea, A. Guerri, O. Fabelo, C. RuizPérez, L.-M. Chamoreau, C. Sangregorio, A. Caneschi, M. Andruh, Cryst. Growth \& Des. 2008, 8, 941; b) D. G. Branzea, L. Sorace, C. Maxim, M. Andruh, A. Caneschi, Inorg. Chem. 2008, 47, 6590; c) J.-P. Costes, R. Gheorghe, M. Andruh, S. Shova, J-M. Clemente Juan, New. J. Chem. 2006, 30, 572; d) D. G. Branzea, A. M. Madalan, S. Ciattini, N. Avarvari, A. Caneschi, M. Andruh, New J. Chem. 2010, 34, 2479.

[15] a) D. Visinescu, A. M. Madalan, M. Andruh, C. Duhayon, J.-P. Sutter, L. Ungur, W. van den Heuvel, L. F. Chibotaru, Chem.-Eur. J. 2009 , 15, 11808; b) R. Gheorghe, A. M. Madalan, J.P. Costes, W. Wernsdorfer, M. Andruh, Dalton Trans. 2010, 39, 4734.

[16] S. Zhao, X. Lü, A. Hou, W.-Y. Wong, W.-K. Wong, X. Yang, R. A. Jones, Dalton Trans. 2009, 9595. 